\title{
ELECTROMAGNETIC IMAGING USING PROBE ARRAYS
}

\author{
Gerhard Mook, Fritz Michel, Jouri Simonin \\ Otto-von-Guericke-University Magdeburg \\ P.O.B. 4120, D-39016 Magdeburg, Germany, \\ mook@ovgu.de,michel@ovgu.de,simonin@ovgu.de
}

\begin{abstract}
Electromagnetic methods like eddy current technique do not provide images but only produce local signals in a difficult to understand measurement plane. Filters, thresholds and phase rotators are common tools of signal processing unable to bring up all information contained in the signals. Trials to generate images comparable to x-rays mostly base on costly and time consuming mechanical surface scanning.

The paper presents theoretical and experimental steps ahead to modular $1 D, 2 D$ and $3 D$ probe arrays for eddy current inspection. In contrary to other attempts these arrays work at low frequencies able to penetrate below the surface and provide good lateral resolution. That way they bring up not only surface but also hidden defects and anomalies. Potential industrial applications are outlined.
\end{abstract}

Key words: All-digital eddy current instrument, eddy current imaging, probe arrays, low frequency

\section{Introduction}

An open coil system fed by an alternating current induces eddy currents in a conductive material. The density and spatial distribution of these currents depends on the coil geometry, the frequency and some material properties like conductivity, magnetic permeability and geometry. The eddy currents build up a responding electromagnetic field interfering with the exciting field. Depending on the resultant field the coil system provides complex valued signals carrying information about the material properties.

To increase the low frequency performance of receiver coil one can use more windings, high permeable ferrite cores or sophisticated balancing of two or more coils. On the other hand, attempts have been made to substitute inductive receivers by new magneto-resistors [1-3]. These elements are able to sense even DC fields. Their drawbacks are non-linearity, saturation, hysteresis effects and the demand for DC offset. For eddy current applications, newly developed inductive receivers perform not worse than magneto-resistors and are easier to handle. Therefore the following paper focuses on inductive systems. 
To generate a fingerprint of the electromagnetic properties of the material a single probe (coil system) scans the surface track by track. The real and the imaginary part of the probe signal are processed according to the material properties of interest [4-6]. The resultant complex signal is displayed correspondingly to the probe position. Within one scan of the probe two pictures may be recorded; one is representing the real part and the other is representing the imaginary part of the signal. Fig. 1 illustrates this method.

The advantage of this single probe scanning is a high quality of imaging due to the constant probe characteristics $[7,8]$. The drawbacks are the expensive scanners and the time consuming imaging process. Additionally, scanners are limited to simply shaped objects like flat or uniaxial bent surfaces. More complicated surfaces have to be inspected manually without imaging.

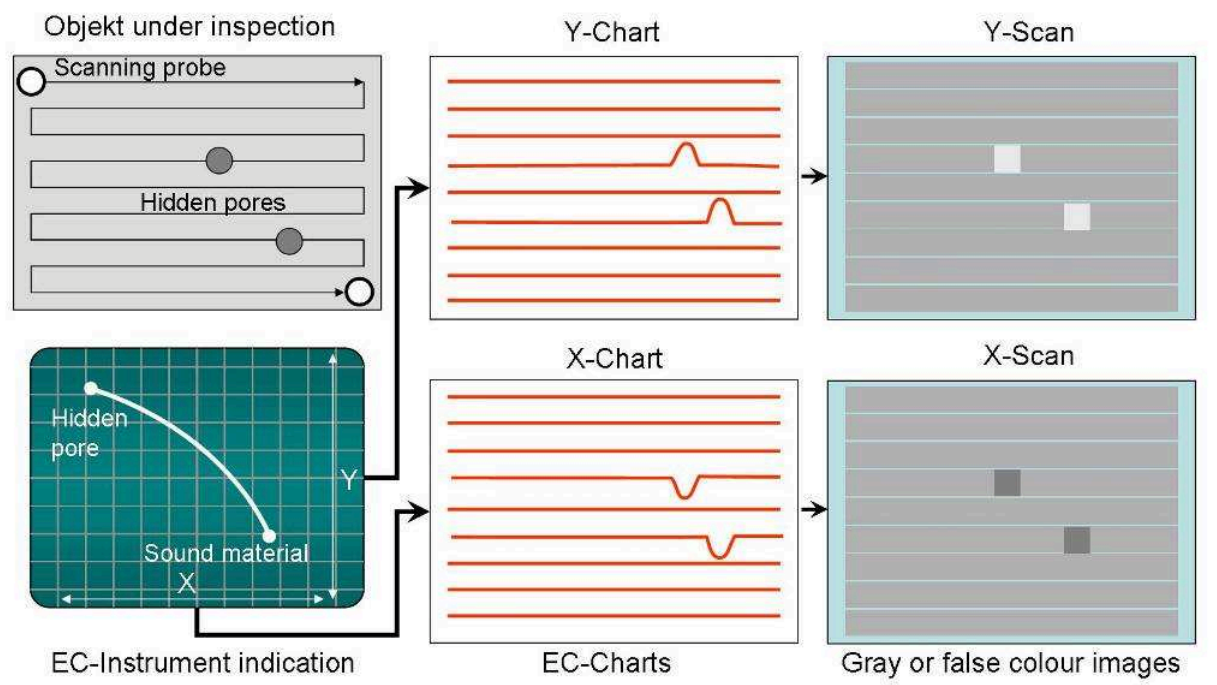

Fig. 1: Electromagnetic imaging using a single scanning eddy current probe

Instead of moving a single probe over the surface one can use an electronically moved field [9-21].

\section{Sensor elements}

\subsection{Point spread functions}

For imaging applications, the point spread function (PSF) of the probe is of most interest. Fig. 2 displays the PSF of some conventional probes widely used in eddy current inspection. With absolute probe a point-like defect is spread to a crater indicating the low sensitivity directly below the probe, called blind spot. The best sensitivity is observed below the edge of the ferrite core. The differential probe provides a bipolar PSF with a blind line along the gap between the receiver coils. Multidifferential probes are well suited for crack detecting of unknown orientation but provide the most complicated and less suited PSF for imaging.

One kind of inductive probes with increased inspection depth is the non-axial transmit-receive probe sometimes called pitch-catch, half transmission or even remote field probe [22]. These probes offer the opportunity to optimize the distance between the transmitting and the receiving coil. Fig. 3 brings up the principle of those probes. The magnetic field of the exciting coil penetrates accordingly to the well known rules of alternating field spreading into the material. The receiving coil only picks up this part of the flux, which has penetrated deeply into the material. The larger the 
spacing between the two coils the deeper the detected flux lines have penetrated into the material but the lower becomes the measurement signal.

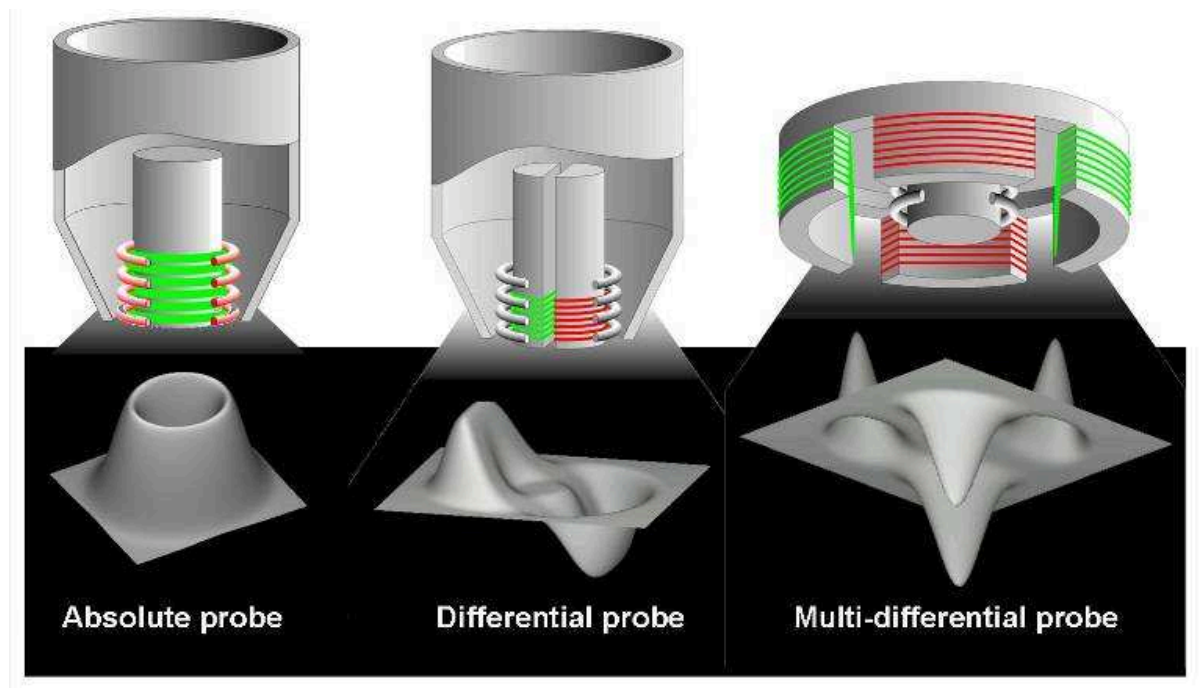

Fig. 2: Point spread functions of conventional eddy current probes

This system of two non-axial coils may be considered as an axial coil system with a diameter corresponding to the coil distance of the non-axial system. With increasing distance (or diameter) of the coils the defect volume decreases relatively to the volume of interaction lowering the signal amplitude. One has to trade off between these parameters.

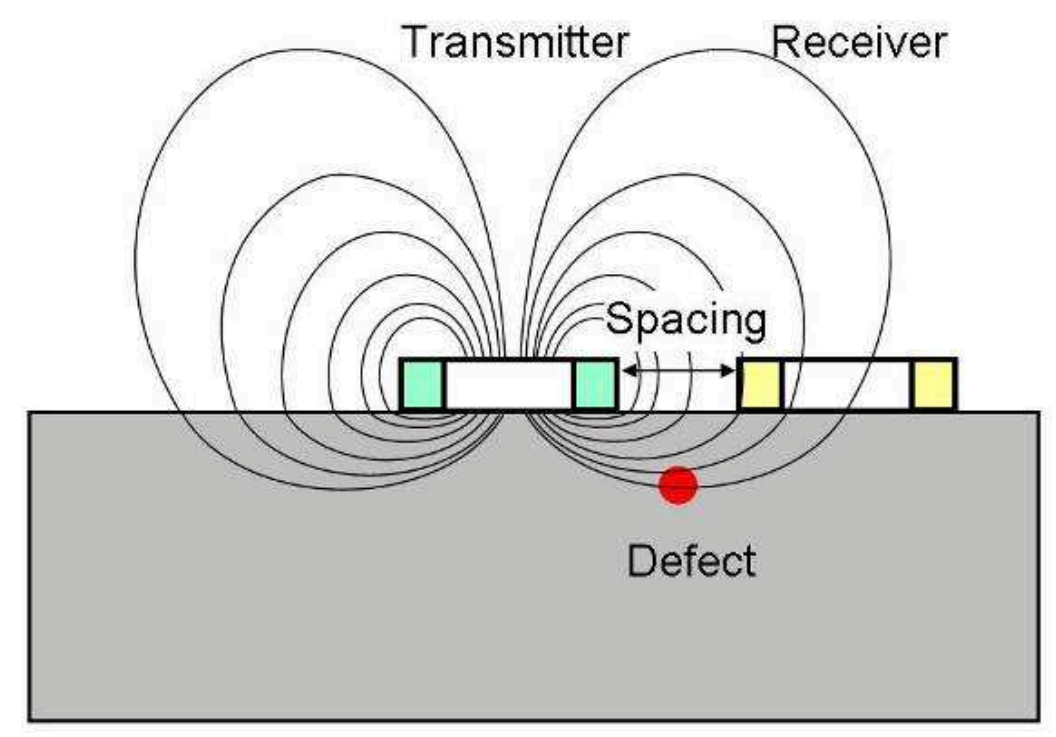

Fig. 3: Non-axial probe selects deep penetration field trajectories

Fig. 4 displays the Point Spread Function (PSF) of this probe. It differs significantly from that of common axial eddy current probes [23] and is most suitable for imaging applications. The shape reminds to a Mexican hat. A sharp positive maximum is surrounded by a negative brim. This shape does not seriously change with increasing spacing between the coils. 


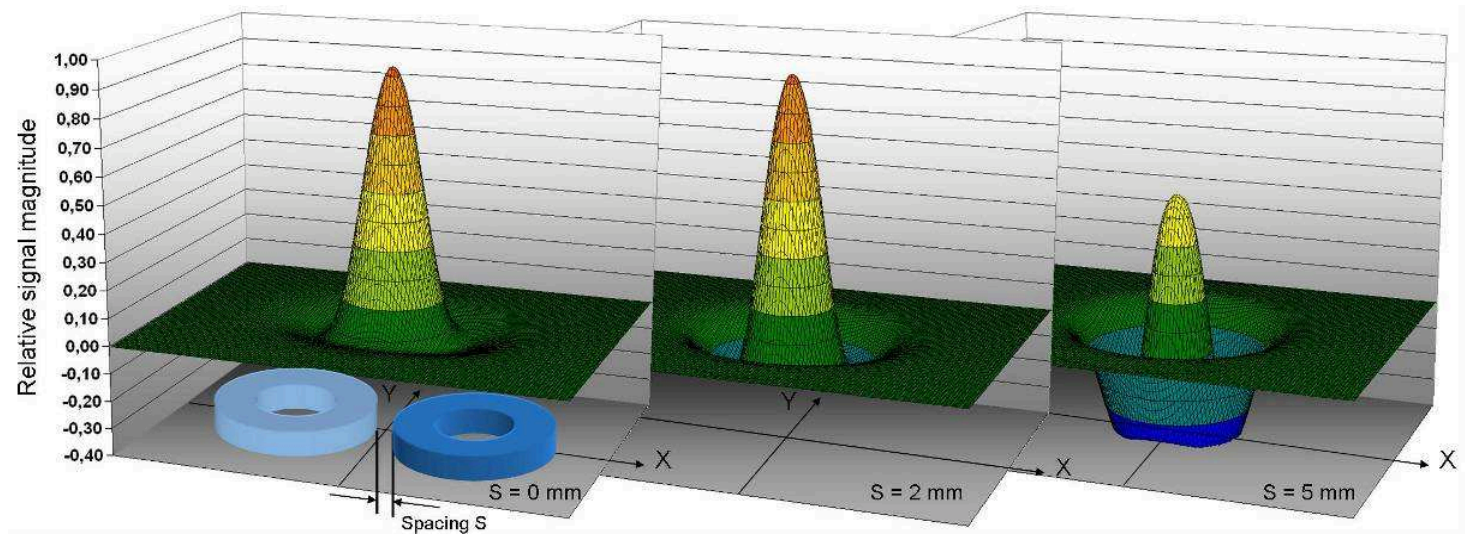

Fig. 4: Calculated signal distribution of a small hidden pore, $\mathrm{z}$ - signal magnitude (arbitrary units), $\mathrm{x}$ and y - position of the pore (VIC-3D, Sabbagh Ass., Inc.)

How the signal magnitude depends on the spacing? To answer this question calculations were conducted with different spacing values. Fig. 5 presents the result in relation to the lift-off signal of $0.01 \mathrm{~mm}$. With increasing spacing the signal ratio only slowly decreases. For hidden defects with more than $2 \mathrm{~mm}$ underlying the signal ratio gains its maximum at a certain value beyond zero.

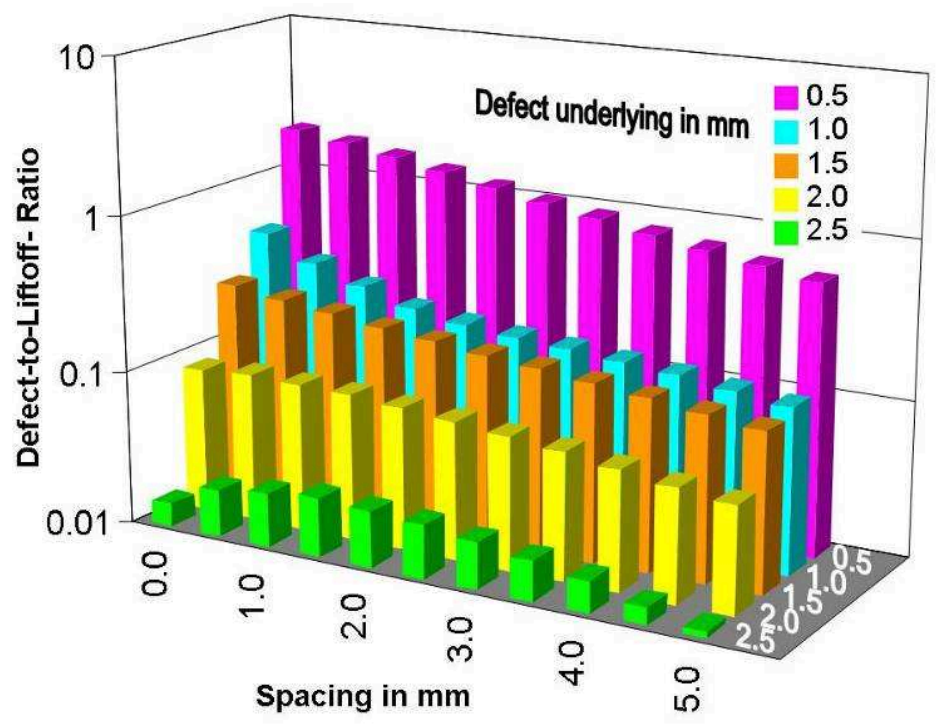

Fig. 5: Relative signal magnitude vs. coil spacing and defect underlying

For assessing the chances for defect characterization the complex values of the measurement voltage were calculated for different inspection situations. Commonly all defect signals are referred to the lift-off signal. For calculating the VIC-3D ${ }^{\circledR}$ code was used.

Fig. 6 brings up the signal behaviour of a pore with defined underlying [24]. Over the sound material the signal is centred at the balance point. When approximating a defect the signal trajectory starts with negative y-values. Just like axial probes the signal turns to positive y-values over the defect. The defect signal turns clockwise with increasing defect underlying. This circumstance opens up the opportunity of assessing the defect underlying. The signal magnitude mirrors the defect volume. 

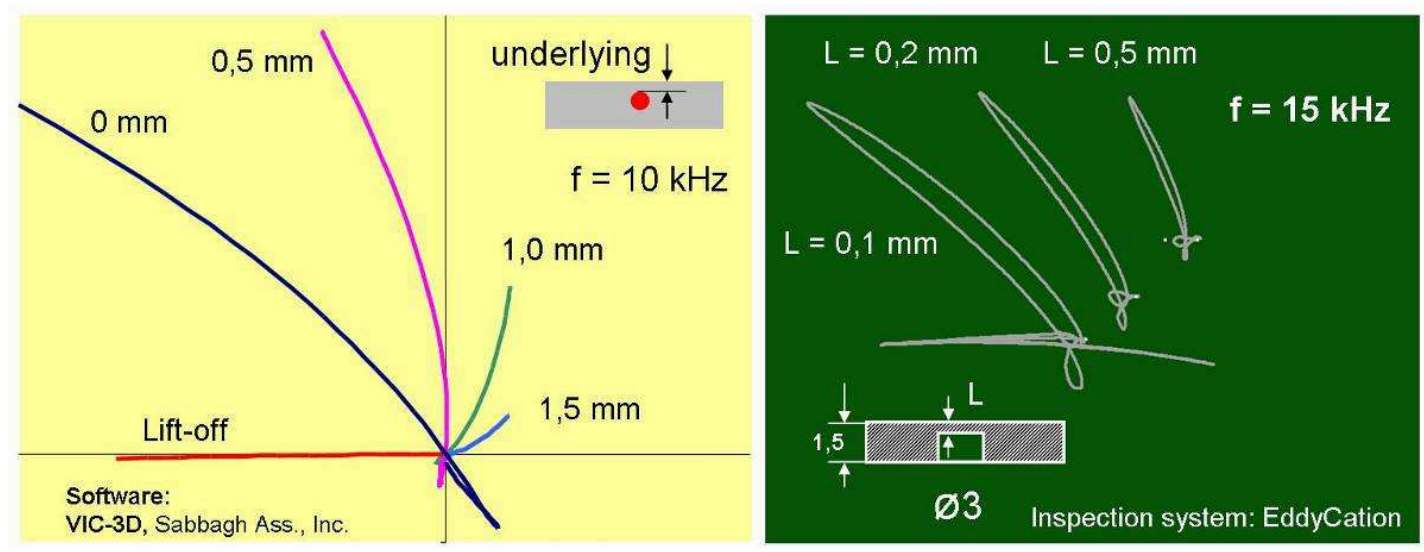

Fig. 6: Complex measurement signal of a pitch-catch-probe moving over hidden pores. Left: calculated signals, right: measured signals.

\subsection{Cascading and operation modes}

Fig. 7 compares the PSF of both probe types cascadable to an array. The pitch-catch probe shown in the left column of Fig. 7 is based on one central transmitting coil and six receiving neighbouring coils. The number of probes formed by this method is more than twice the number of coils. The single core probe in the right column of Fig. 7 spreads its magnetic field also to all neighbours but is recorded by the transmitting element. The number of probes equals the number of cores. This way, two operation modes may be used: the pitch-catch mode and the single core mode. In any mode a transmitter separator switches the transmitting coils and a receiver multiplexer switches the receiver coils. Both work independently each from other. In any time slot only one probe is active.

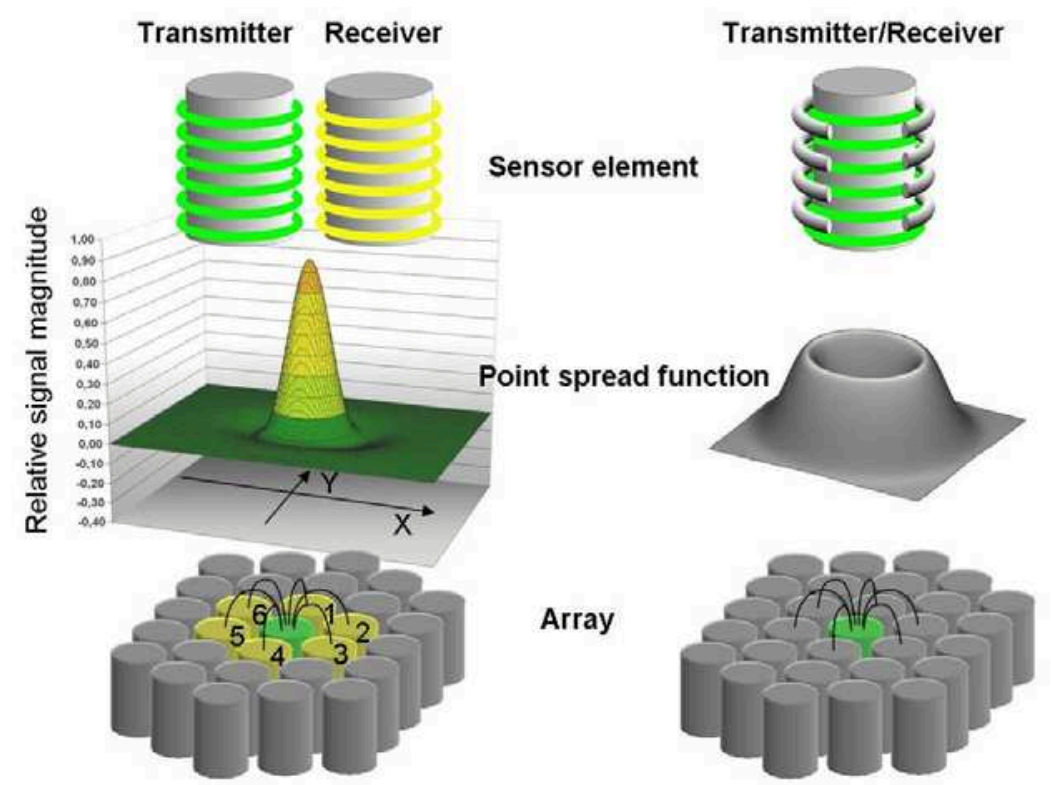

Fig. 7: Bimodal sensors, their Point Spread function and cascading to an array. Left: Pitch-catch probe, right: single core probe (parametric or transformer) 
In contrary to single probes used in conventional applications the probes in an array interact. Intended or unintended the magnetic field of a transmitting coil is guided by the neighboured cores. Fig. 8 shows this situation for the pitch-catch mode. The field of a single pitch-catch probe in Fig. 5a) concentrates the magnetic field of the transmitting coil (green) to the core of the receiving coil and the sensitivity of the probe is $100 \%$. When cascading the coils along a probe line the transmitted field is distributed to two neighbours (Fig. 5b) although only one of them is active in every time slot. The flux through the passive neighbour remains unused. This way the usable flux and the sensitivity reduce to one half. When arranging two shifted lines the flux through the active element diminishes to one quarter and in a complete two-dimensional array to one sixth. This fragmentation of the flux reduces the effect of flux enhancement by ferrite cores. This drawback of rod cores can be avoided by pot cores but here spatial resolution will be lower due to the larger diameter of these cores. Alternatively, air coils could perform close to that of rod cores and are worth for further investigation.

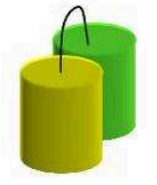

a)
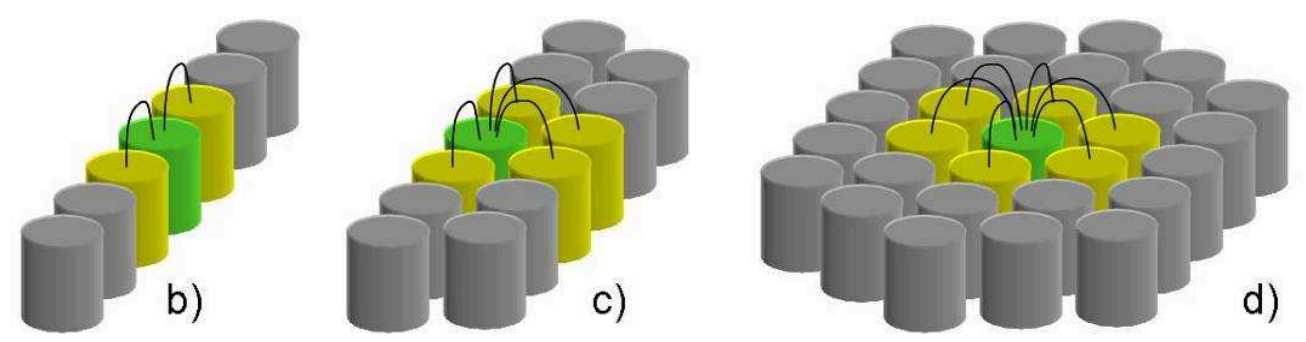

Fig. 8: Fragmentation of the magnetic flux to a) one, b) two, c) four and d) six neighbours

Concerning the quality of imaging, the spatial resolution plays an important role. In the single core mode every coil corresponds to one probe, the spatial resolution is that of the core density. Along a probe line the PSFs are superimposing like shown in Fig. 9 above. The part below explains, that in the pitch-catch mode the spatial resolution along a probe line is twice as high.
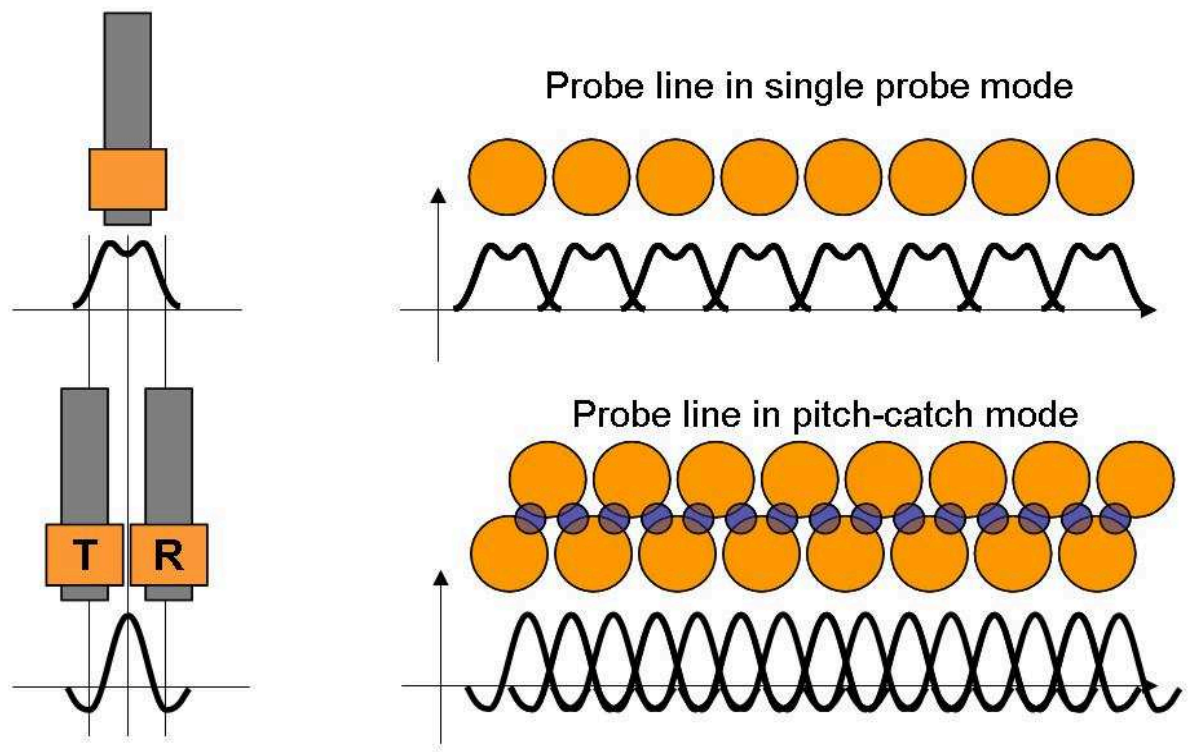

Fig. 9: Spatial resolution in single mode (above) and pitch-catch mode (below) 


\section{Probe lines}

Two probe lines have been manufactured each consisting of 32 and 64 rod core coils respectively [24-30]. The speed of electronic field movement ranges from 0.3 to $3 \mathrm{~m} / \mathrm{s}$ according to the inspection requirements. To visualize a certain area of the workpiece the sensor line must be guided over the surface. When handled manually a measuring wheel connected to the sensor picks up the distance. In automatic inspection a robot can guide the sensor with constant velocity from 6 to $48 \mathrm{~mm} / \mathrm{s}$. Fig. 10 displays the probe lines and Fig. 11 shows their components. The eddy current instrument is reduced to a multiplexer and an AD/DA-converter. All necessary electronics is united in the probe housing. A simple USB cable connects the probe line to a notebook. All other components and functions are addressed to the software.

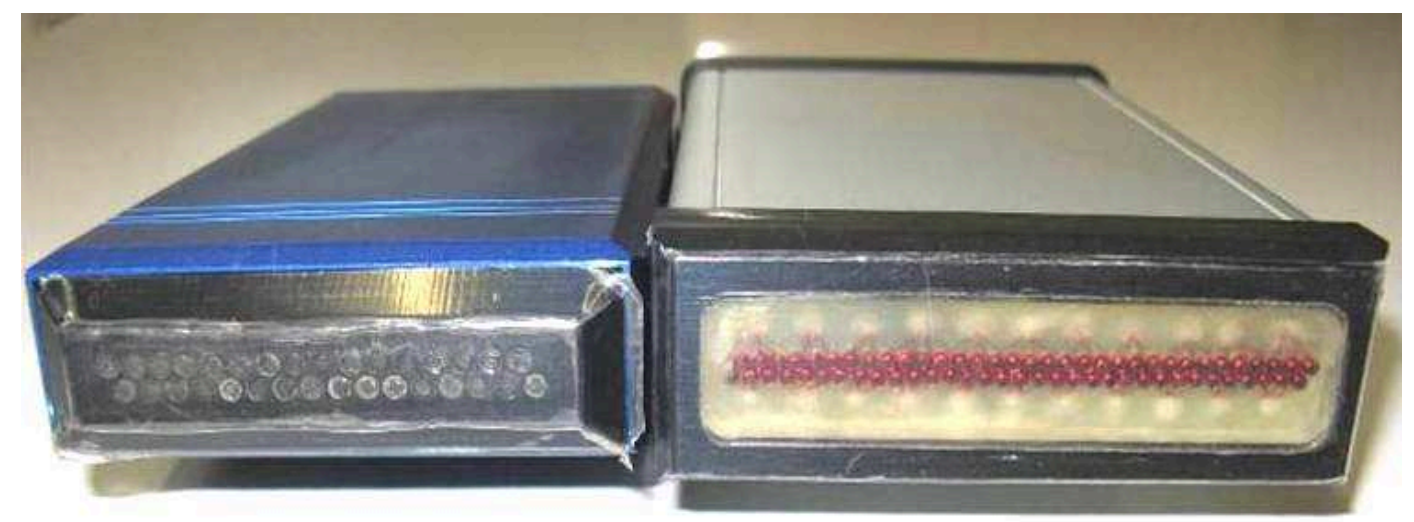

Fig. 10: Left: Array probe 32, 1.5-mm-ferrite rod cores, pitch-catch mode, coil centre distance $3 \mathrm{~mm}$, total track width $45 \mathrm{~mm}$, probe centre distance $1.5 \mathrm{~mm}$, right: Array probe 64, 1.05-mm-ferrite rod cores, pitch-catch mode, coil centre distance $2 \mathrm{~mm}$, total track width $61 \mathrm{~mm}$, probe centre distance ca. $1 \mathrm{~mm}$

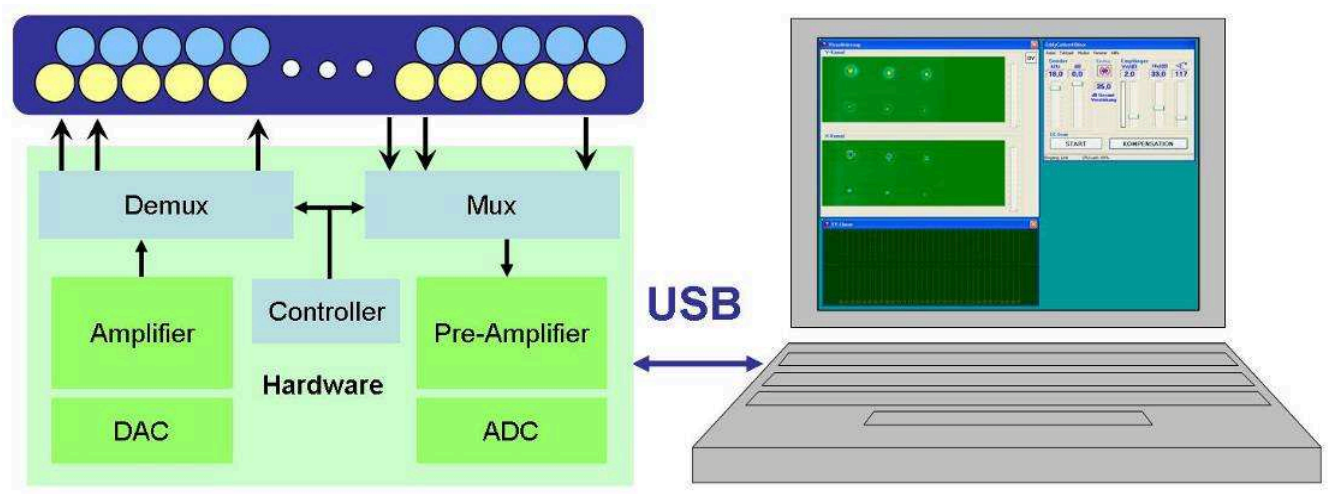

Fig. 11: Hardware components of the probe lines

Fig. 12 presents a first result of detecting hidden holes in an aluminium plate simulating hidden pores in aluminium casts. The underlying varies from 0.1 to $0.5 \mathrm{~mm}$. The adjustment of the eddy current signals is chosen in a common way. The lift-off signal is turned horizontally to the left in the $\mathrm{XY}$-plane. All holes can be visualized in a gray scale or false colour image. 


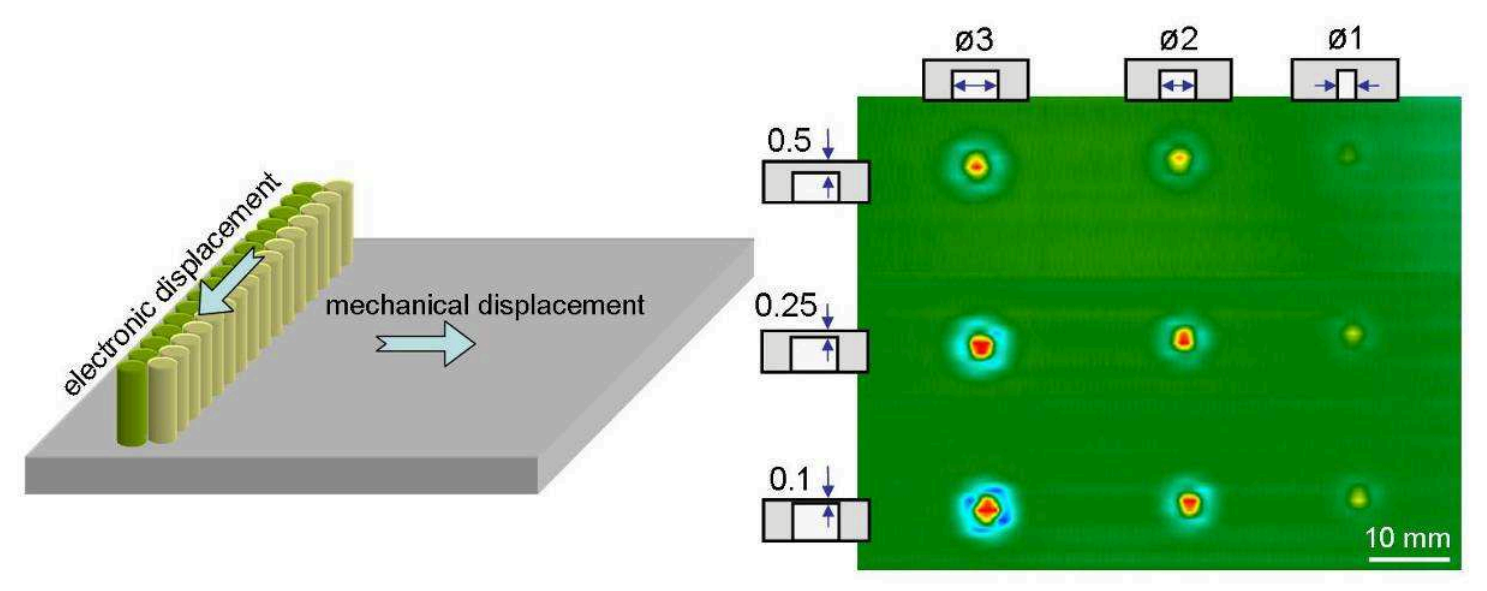

Fig. 12: Visualization of hidden defects in aluminium, left: moving field sensor, right: y-component image of the plate

For more detailed evaluation of the hidden defects the depth of underlying can be colour coded. This depth is represented by the phase angle of the defect signal. Fig. 13 shows, how this phase angle can be converted into a colour with clear association to severity of the defect. The closer a pore comes to the surface the higher the probability of opening this pore during machining. The left part of Fig. 13 displays three signals of 1-mm-holes simulating hidden pores. The closest underlying provides the leftmost signal, the farthest gives the rightmost. Of course, with increasing underlying the signal amplitude diminishes. Pores of the same diameter provide decreasing amplitudes and clockwise turning signals with increasing underlying. For a suitable colour coding the phase shift and the signal amplitude should determine the colour and the saturation respectively. The maximum saturation should be gained with diminishing amplitudes [25].

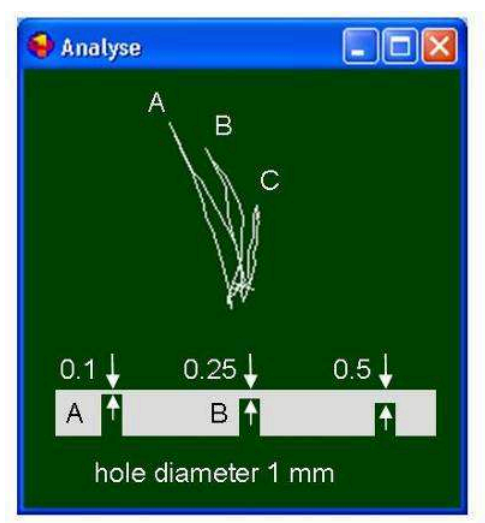

Signals of hidden holes in the XY-plane

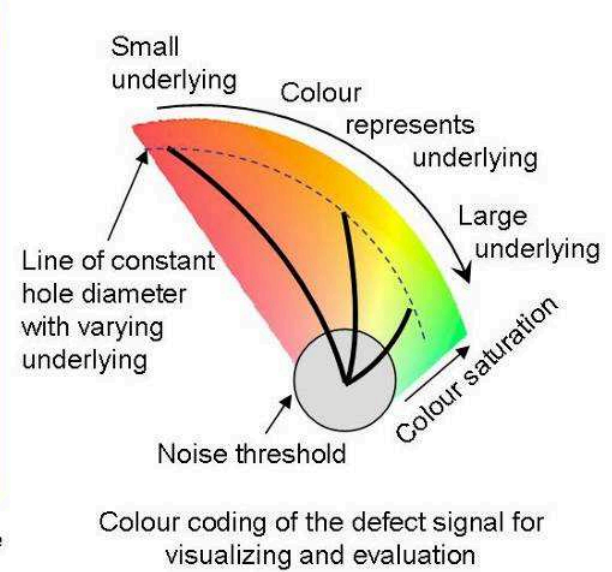
visualizing and evaluation

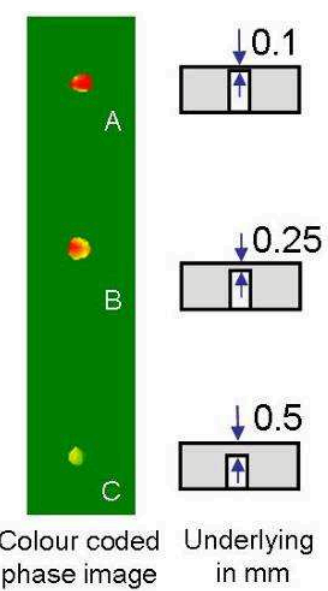

phase image in $\mathrm{mm}$

Fig. 13: Indication of three hidden holes simulating hidden pores. Left: indication in the $\mathrm{XY}$-plane, middle: translation of angle into a colour, right: the resultant image brings up the closest defect in red, the farthest in green.

For further assessment of the probe line an aluminium sheet was engraved with letters and signs simulating defects of different size and orientation (Fig. 14 left) [29, 30]. The first number in every 
line indicates the height of the font in millimetres. Moving the line sensor over this reference sheet we will get its "eyesight test".
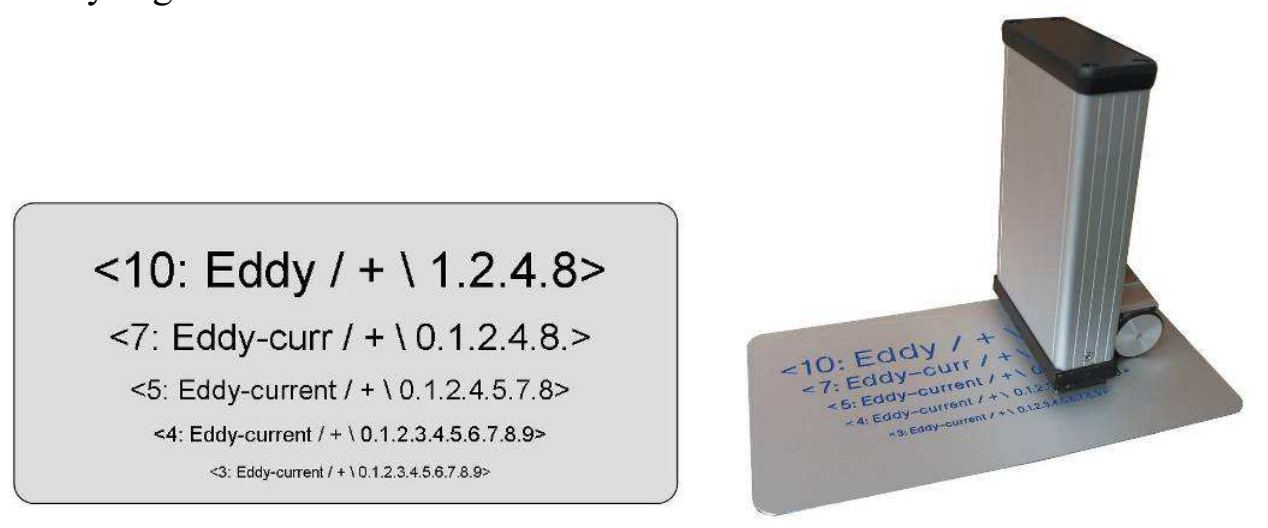

Fig. 14: Left: Engraved aluminium sheet as reference. The first number in the line indicates the font size in millimetre, right: array probe 64 with measuring wheel on the sheet.

When the engraving is turned up (Fig. 15a) the array probe 32 ends up with font size 5. The Fig. 15b brings up the performance when "looking" through a sound 1-mm-aluminium sheet on the engraving. The signal-to-noise-ratio is lower but big enough for reading the font down to size 7 . The Fig. $15 \mathrm{c}$ and $15 \mathrm{~d}$ display the readability with turned down engraving. The largest underlying is reached in Fig. 15d with an additional coverage of a sound 1-mm-sheet. Here, the signal-to-noise ratio is reduced significantly but the size 7 may be read anyway.

Summarizing this investigation, all parts of the letters and signs can be read independently of their orientation despite the anisotropy of the probe elements of the array.

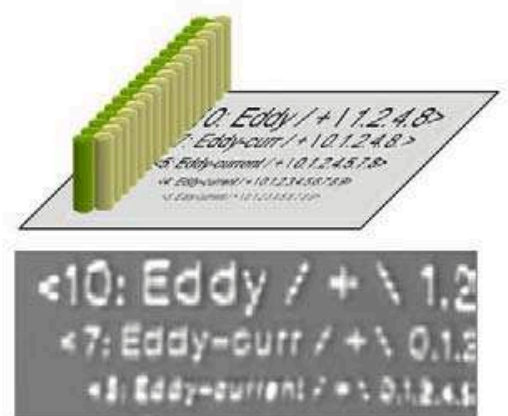

a)

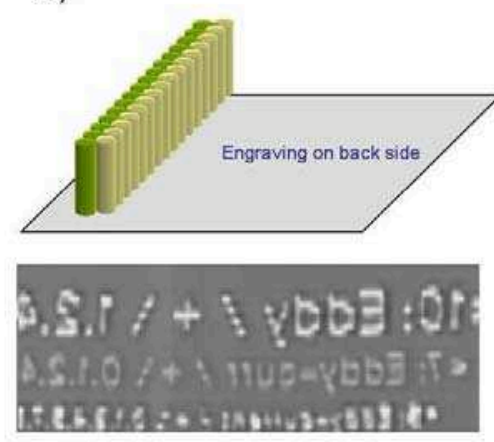

c)

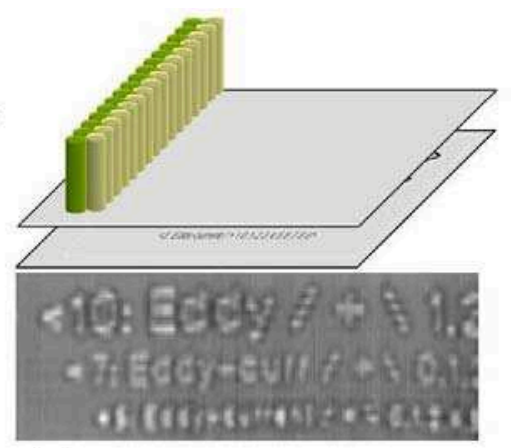

b)

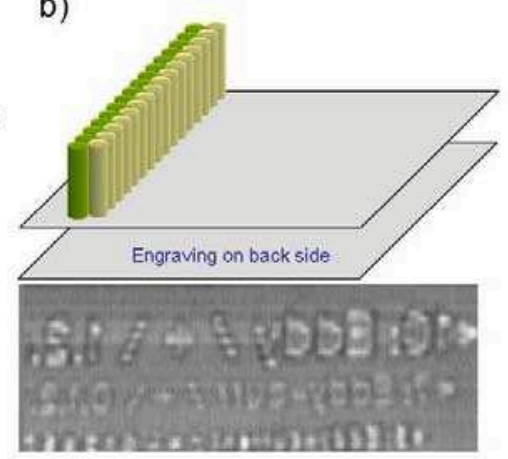

d)

Fig. 15: Eyesight test of the probe array 32 
Fig. 16 compares the spatial resolution of the probe arrays 32 and 64 . With the array 64 most signs of the smallest font size 3 can be read.

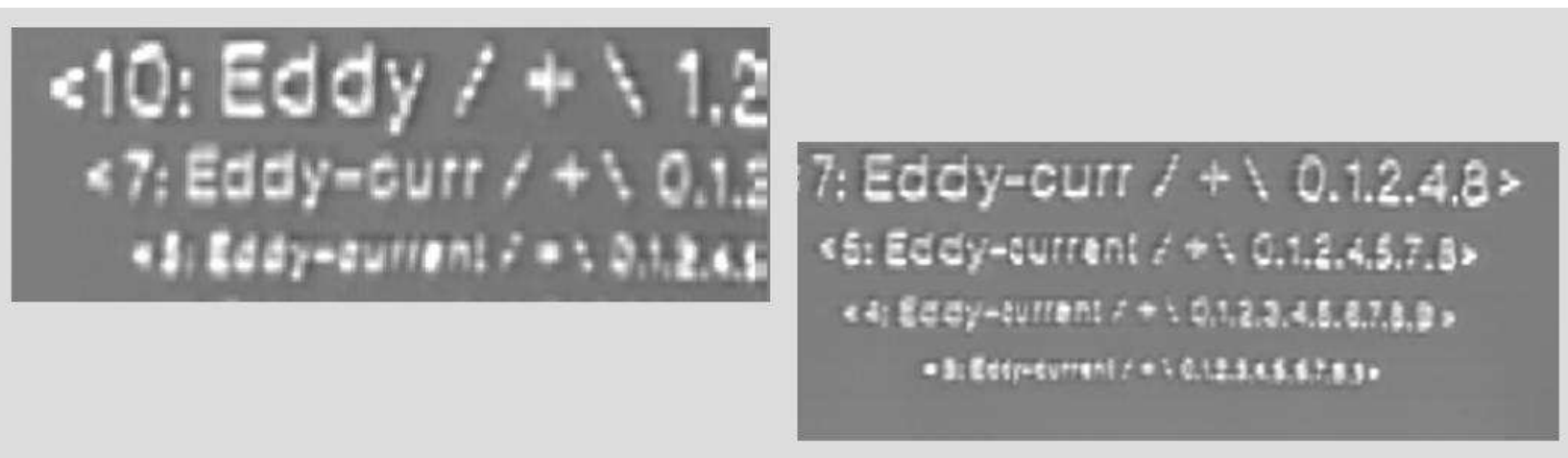

Fig. 16: Comparison of spatial resolution of the probe arrays 32 (left) and 64 (right)

Fig. 17 displays a real aluminium cast with hidden anomalies. The photograph in Fig. 17a does not show any anomalies. The eddy current images recorded by the probe array 32 bring up patterns of local conductivity variations as points and a closed loop. The phase image indicates different underlying. After $1 \mathrm{~mm}$ rework the loop-like pattern becomes visible.

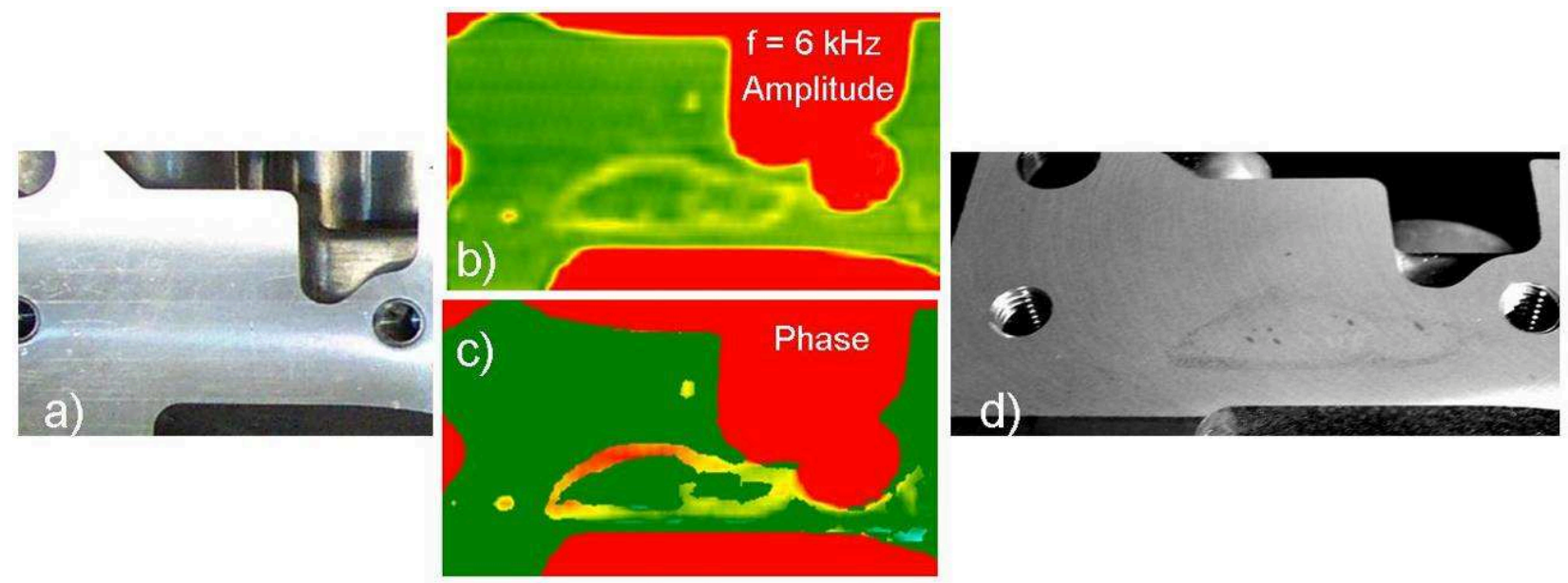

Fig. 17: Visualization of hidden anomalies in aluminium cast: a) Photograph of the area of interest, b) electromagnetic amplitude and c) phase signature of this area, c) Photograph after $1 \mathrm{~mm}$ rework brings up the anomaly visually.

Fig. 18 shows the eddy current images of two aluminium engine blocks. The outer shape can be recognized as well as 5 drilling holes. Besides this, in every casting pore-like and loop-like anomalies can be seen. 


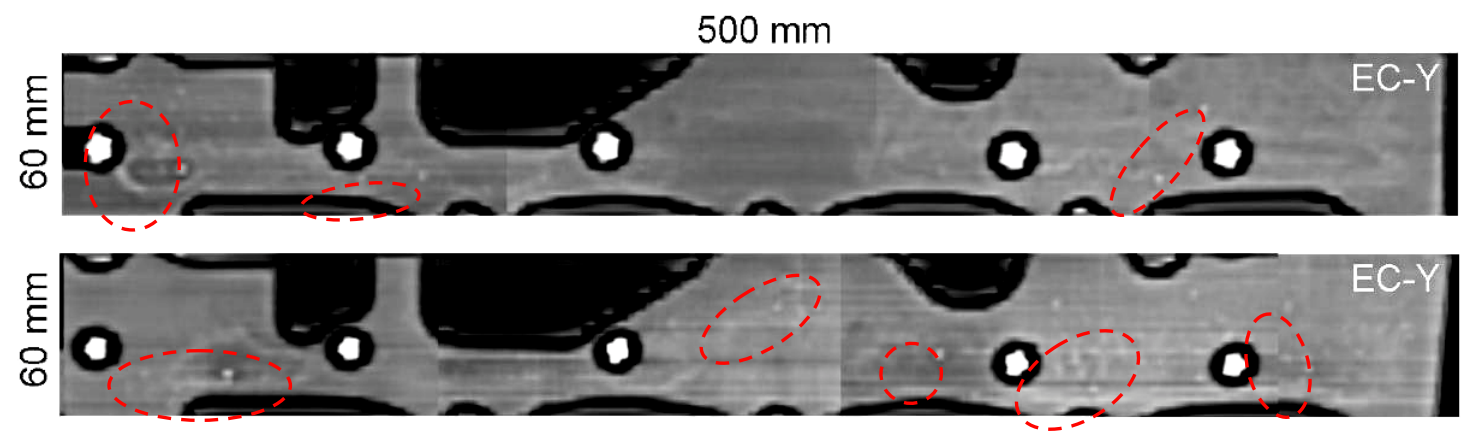

Fig. 18: Visualization of hidden anomalies in two aluminium engine blocks.

Fig. 19 summarizes the results of aluminium squeeze castings. The bright spots in the indicated areas correspond to open and hidden defects. The other objects are drilling holes and outer shape.

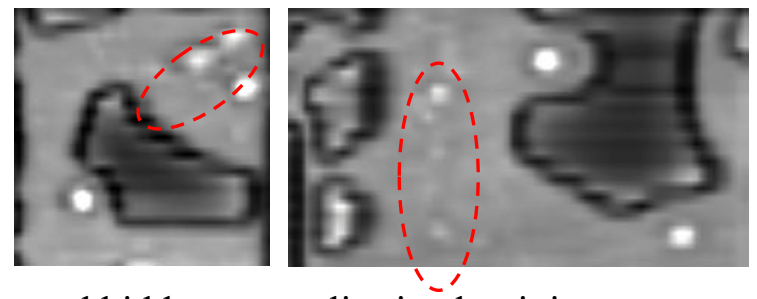

Fig. 19: Open and hidden anomalies in aluminium squeeze castings

For curved surfaces eddy current array probes also may be fitted. Fig. 20 gives some ideas for convex objects like pipes, rods or rails.

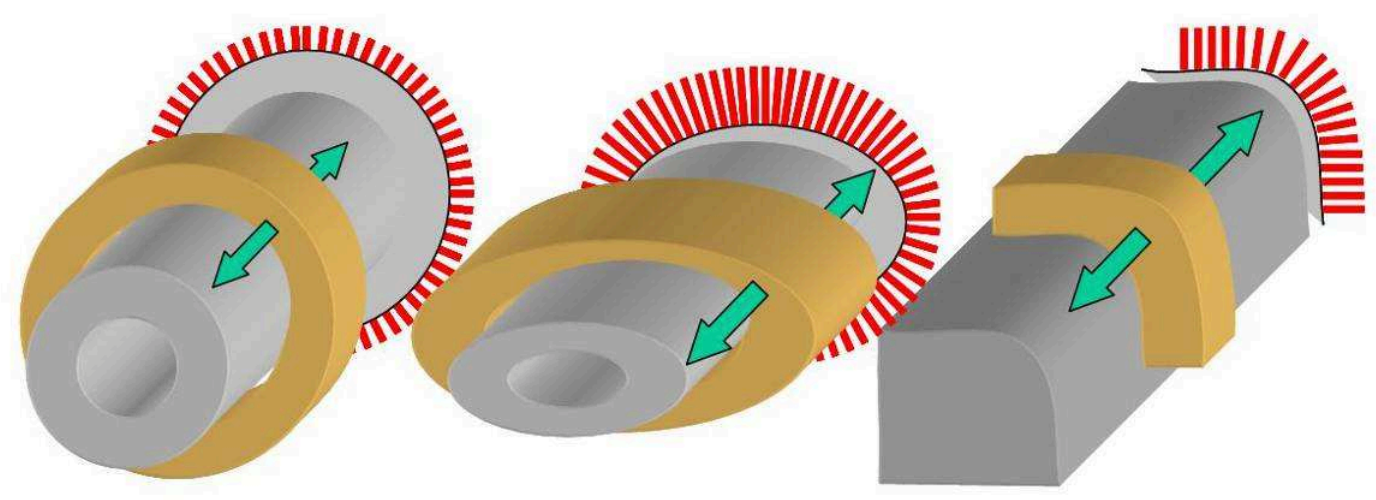

Fig. 20: Potential applications of probe arrays for curved surfaces

\section{Flat arrays}

The principle of multiplexed coils may be extended to 2D-arrays [24-30]. Fig. 21 presents a flat array with a sensitive area of $38 \times 44 \mathrm{~mm}$. The array electronics contains the 256-channel eddy current instrument and communicates with a Windows-Notebook via USB. The array need not be moved during imaging. 
The sensors may work in two different modes. In half-transmission mode each coil corresponds with its neighbours ( 705 sensors), in single core mode each coil works separately (256 sensors).

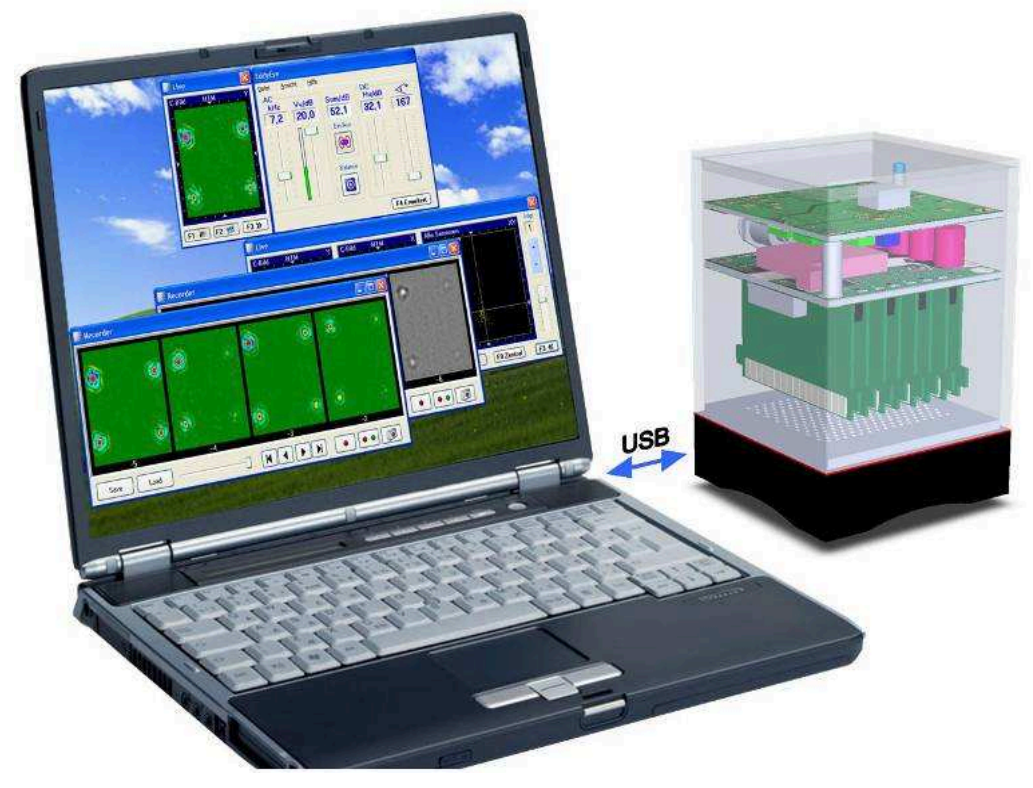

Fig. 21: Flat array consisting of $16 \times 16$ coils working as 961 sensors covering an area of 38 x $44 \mathrm{~mm}$. Dimension of the array housing: W x D x H $=60 \times 60 \times 82 \mathrm{~mm}$.

The aluminium sheet in Fig. 14 was scanned by this array. Fig. 22 shows the results. Although the resolution is a little lower than that of the probe line all reference defects can be recognised. The build-up time is 0.64 seconds providing an image refresh rate of $1.56 \mathrm{~Hz}$.
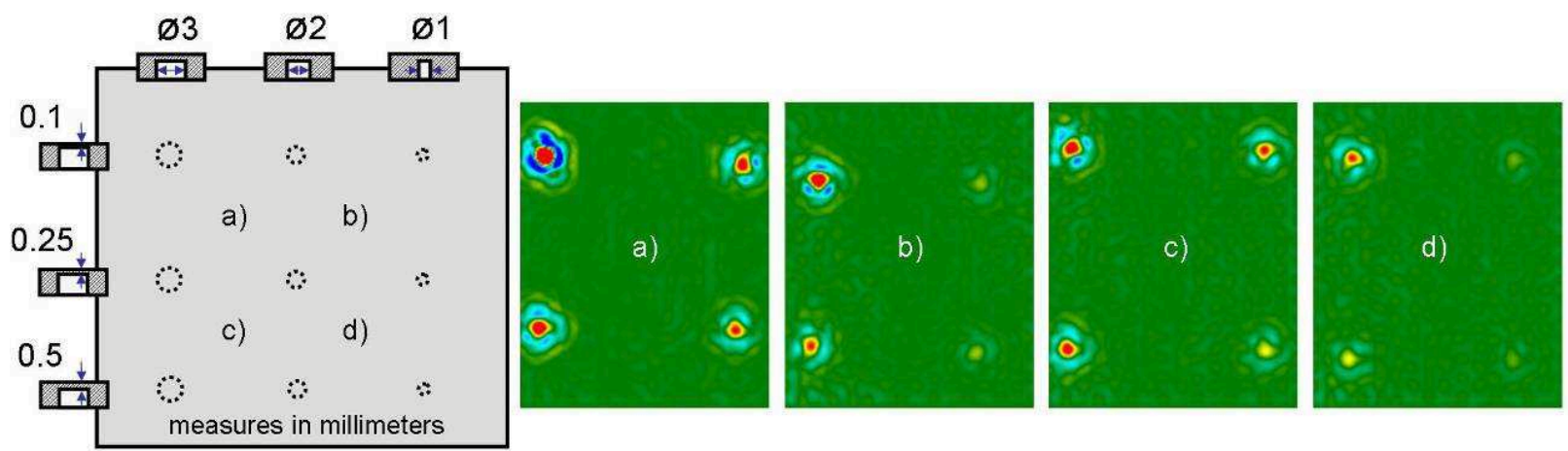

Fig. 22: Visualization of hidden flat bottom holes in an aluminium sheet (conductivity $21 \mathrm{MS} / \mathrm{m}$ ) using the 2D-sensor array. Left: sketch of the sheet, right: electromagnetic images of 4 sections each covering $38 \times 44 \mathrm{~mm}$

Fig. 23 presents a photograph of the array and gives an example of hidden corrosion detection. Here, the single core mode was selected giving a clear image of the shape of the corroded area. Again, the angle of the signals corresponds to the underlying of the defect. 

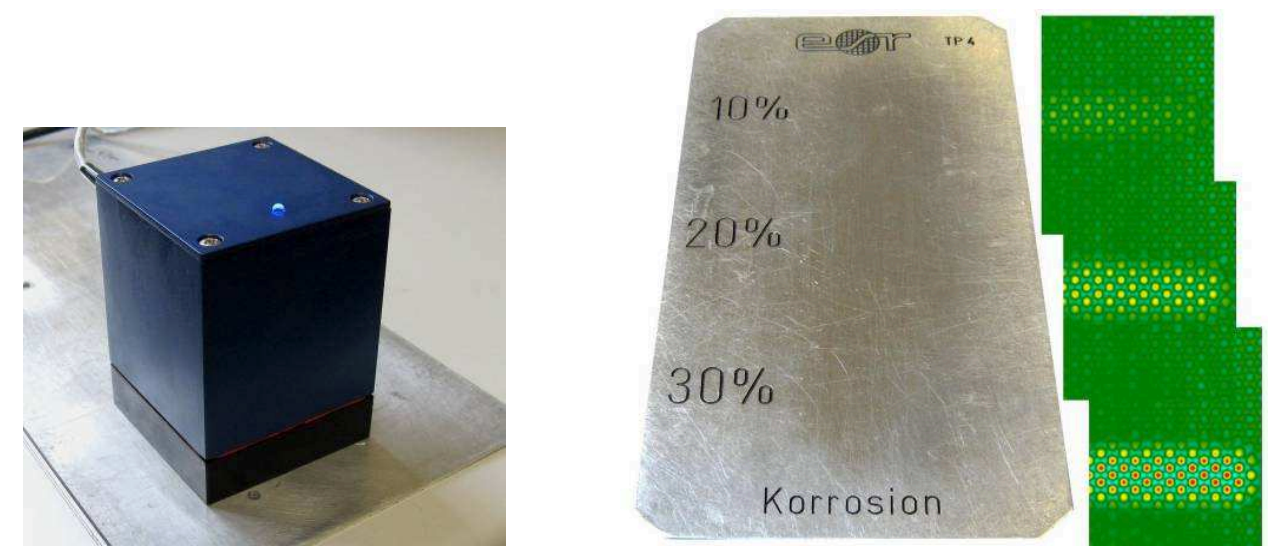

Fig. 23: Photograph of the array and results of hidden corrosion in an aluminium sheet.

For increasing the signal-to-noise-ratio the software can integrate over a selectable number of subsequent images. The images may be stored for quality documentation or defect growth analysis. Basing on the magnitude and the angle of the defect signal in the complex measurement plane defect classification becomes possible.

\section{Free-form array}

Although not flexible the coil arrangement may be adapted to the inspection surface by moulding techniques. Once moulded and cured the array forms a solid body easy to handle. As an example a spherical surface was transferred to the array. Fig. 24 gives an idea of the array and the aluminium reference.
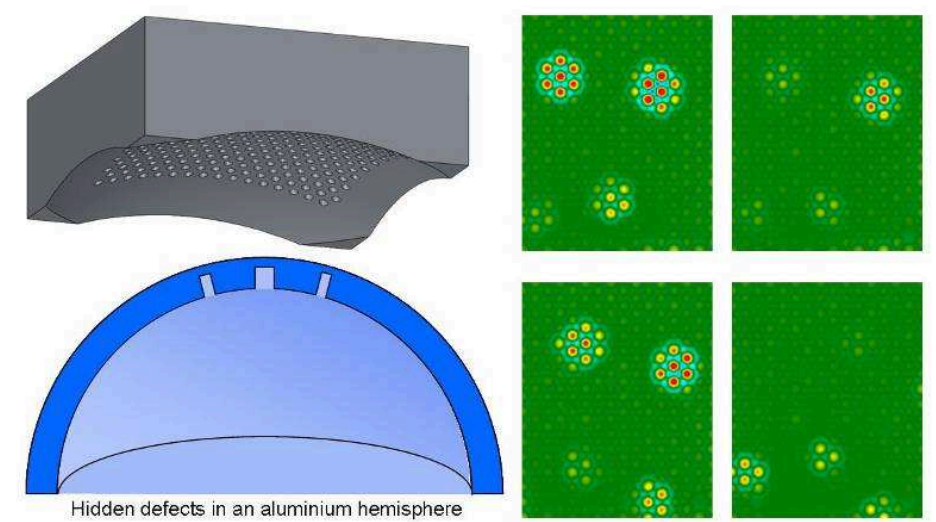

Fig. 24: Visualization of hidden holes in an aluminium hemisphere using a free-form sensor array.

Left top: Sketch of the array, left bottom: sketch of the reference,

right: electromagnetic fingerprints of the defect area

Further potential applications are shown in Fig. 25. On the left side a corner is inspected covered by a dedicated array. On the right side an array covers a part of a turbine blade. 

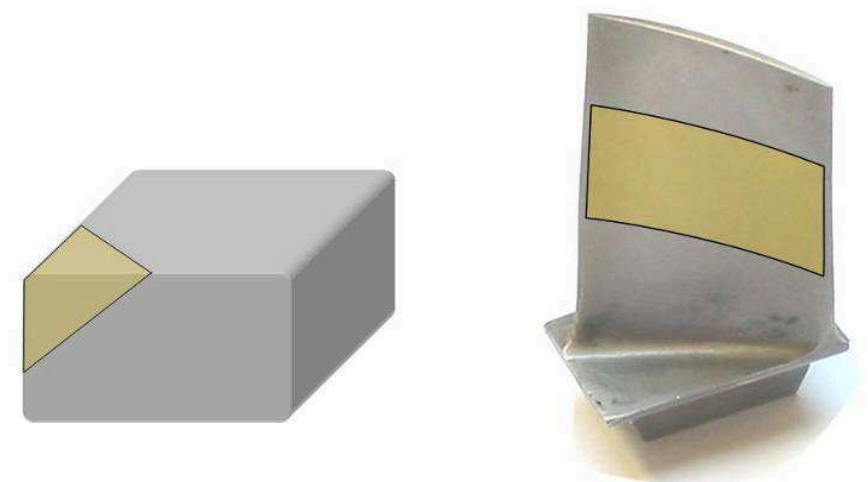

Fig. 25: Potential applications of free-form arrays on complex surfaces

\section{Micro-Scanning}

When put on the engraved aluminium sheet (Fig. 26) the array provides images shown in the four right frames of Fig. 27. The individual sensors can be recognized in the image. Only the 10-mm-font and partially the 7-mm-font can be read.

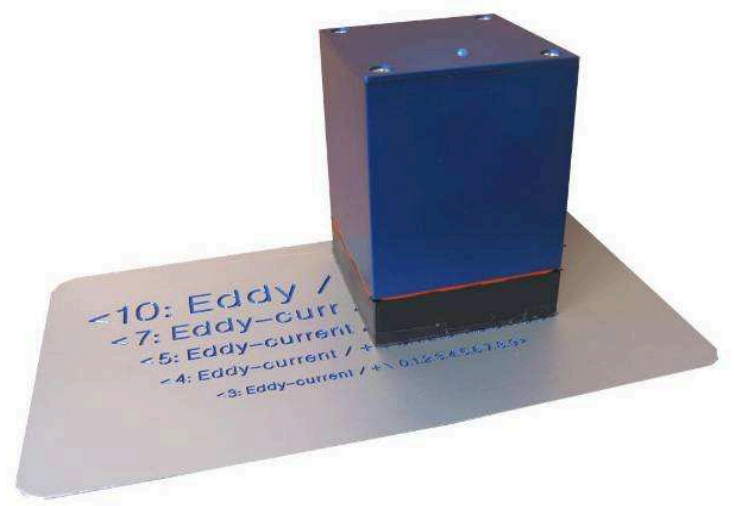

Fig. 26: The flat array on the engraved aluminium sheet for testing the spatial resolution

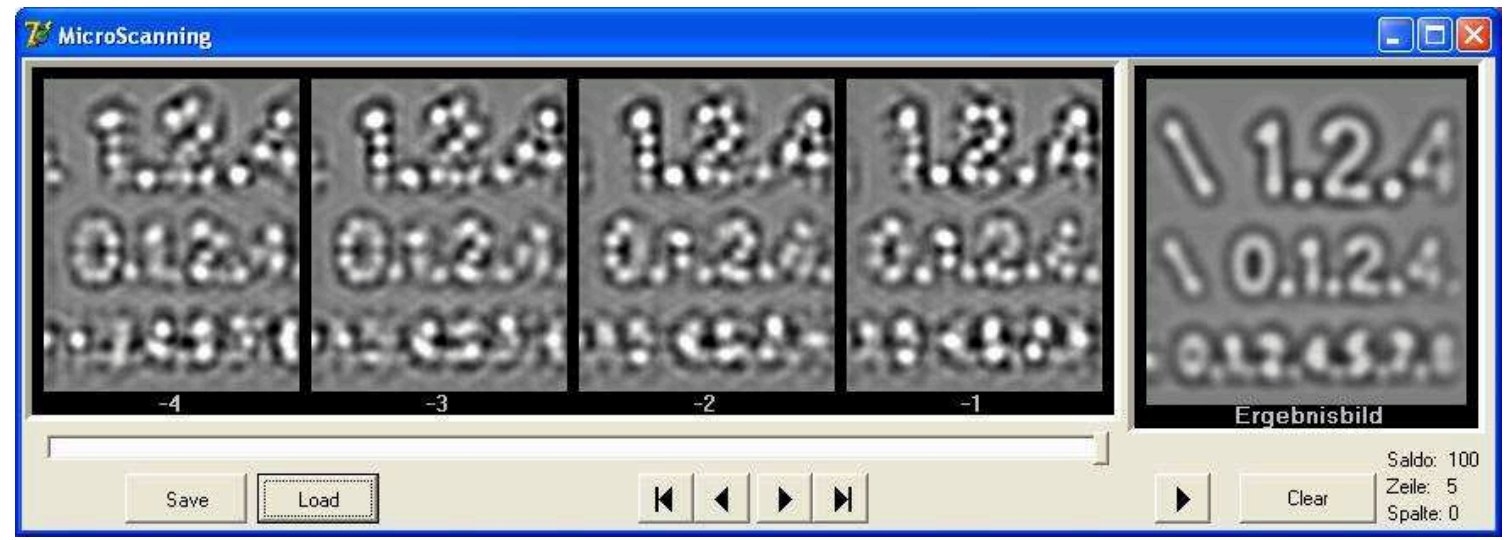

Fig. 27: Images of the flat array in pitch-catch mode on the engraved aluminium sheet. Left: Sequence of 4 eddy current images gathered with minimal shift of the array by $0.5 \mathrm{~mm}$. Right: Weighted images following the principles of micro-scanning. 
The idea of micro-scanning [29, 30] consists of moving the array by steps, much lower than the distance between the single sensors and accumulate a weighted resultant image. When moved by $0.5 \mathrm{~mm}$ steps the resultant image is much clearer and less noisy than every of the original images. The right frame in Fig. 26 gives the evidence of the increase in readability down to the 5-mm-font. The dark halo of every sign is the result of the Mexican hat PSF.

When turn down the engraving and cover it by a sound aluminium sheet a single frame does not provide readable results. The existence of the engraving can be recognized hardly. The microscanning enhances the readability so, that most of the 7-mm-letters can be read. Of course they are mirrored (Fig. 28).

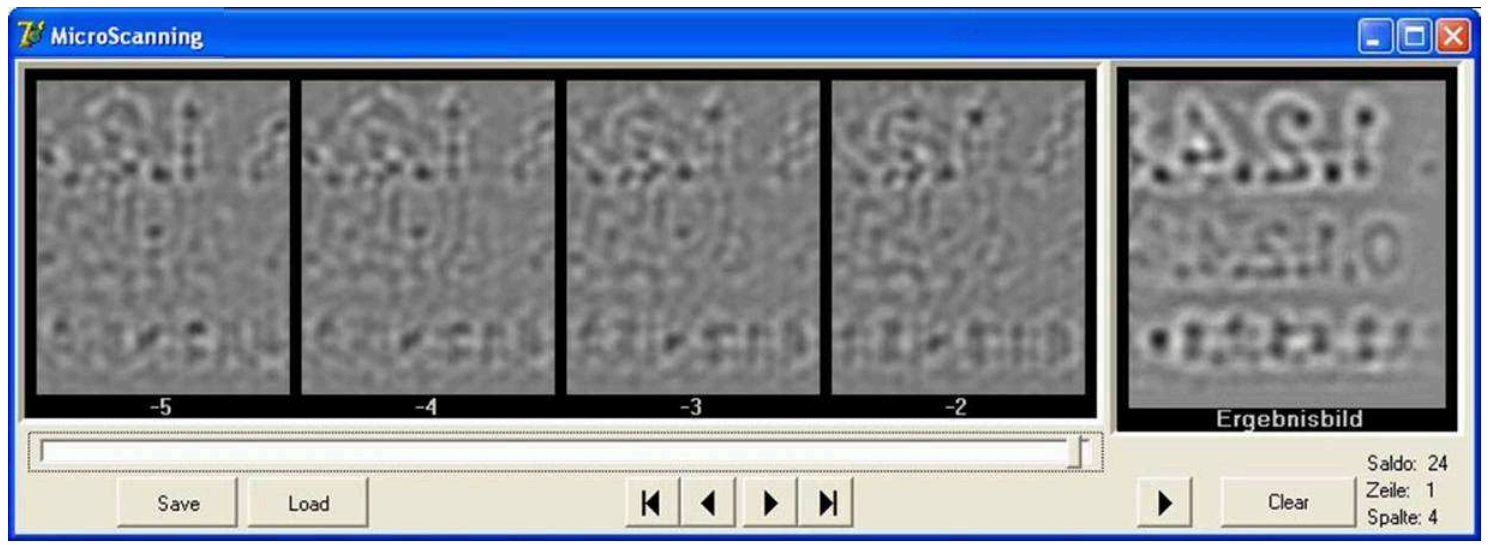

Fig. 28: Engraving on the bottom of the second layer. Left: Sequence of 4 eddy current images in pitch-catch mode gathered with minimal shift of the array by $0.5 \mathrm{~mm}$. Right: Weighted images following the principles of micro-scanning.

The potential of micro-scanning is demonstrated in Fig. 29 using the single core mode. Here, the distance of individual sensors is $3 \mathrm{~mm}$ and the engravure directly cannot be read. Simply moving the array in horizontal direction over the engravure, the micro-scanning easily lets recognize the 7-mmletters of the second line.

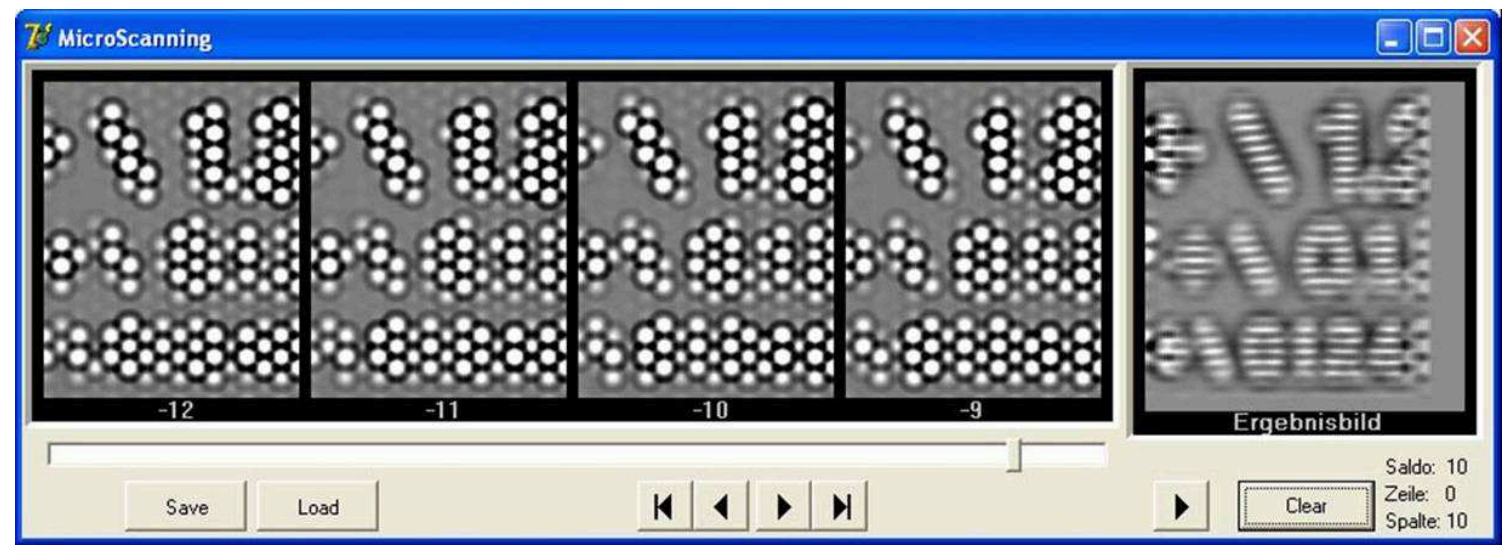

Fig. 29: Single core mode of the flat array. Left: Sequence of 4 eddy current images in pitch-catch mode gathered with minimal shift of the array by $0.5 \mathrm{~mm}$. Right: Weighted images following the principles of micro-scanning merely in horizontal direction. 
For this micro-scanning the displacement of the array should be measured. Among the possible solutions we find mechanical systems like wheels or optical systems like sensors known from computer mice. These sensors calculate the displacement using two or more subsequent images of the substrate. Known techniques like differential image processing and 2D-correlation algorithms are implemented in a special processor inside the mouse. This method requires a difference in the treated images. When missing this difference the sensor is blind. This effect is known from computer mice when moved on smooth and unstructured surfaces.

This principle of relative displacement measurement also can be accomplished by the eddy current probe array. Again, a structured area of inspection is needed. This "structure" may be provided even by defects. The array visualizes the movement of the defect and calculates the displacement of the array in $\mathrm{x}$ - and $\mathrm{y}$-coordinates. When the object is free from defects or any other structure seen by eddy current method, the displacement cannot be picked up.

For some applications this restriction can be accepted. If only defect documentation is needed, the position of the array is not required. For complete visualization of the inspection area the position of the array always should be known. For this application the array is equipped with a laser mouse sensor nearly working on all surfaces. Fig. 30 explains how an array can fill the whole area of inspection without any gaps.

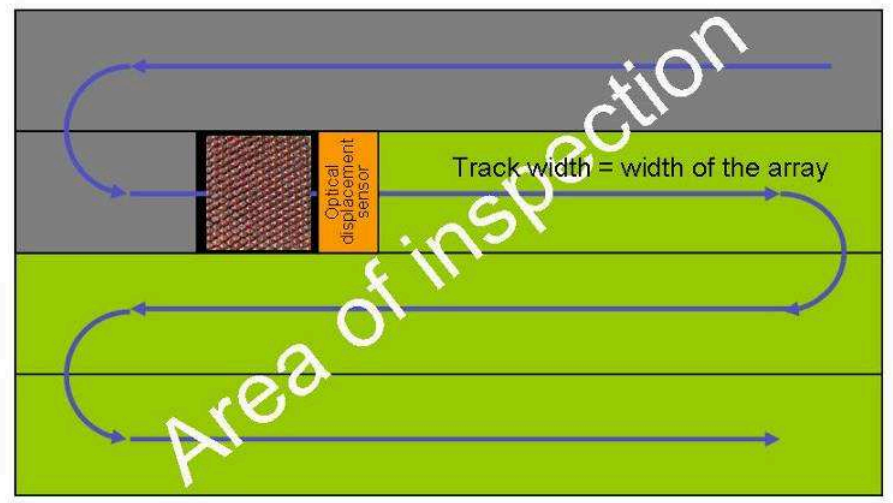

Fig. 30: Covering the area of inspection by a probe array track by track. An optical mouse sensor records the relative position of the array and helps to stitch the track images.

The micro-scanning has another advantage even in this situation. When scanning large areas the array may be moved fast. If there is any indication the sensor is moved slower and the image quality automatically will enhance for good visualization and documentation. This way, an optimum between inspection speed and image quality is found.

\section{Conclusion}

The moving electromagnetic field sensor visualizes open and hidden defects saving all advantages of eddy current inspection. Compared with single probe scanners the handling becomes much easier and cheaper. The eddy current hardware is reduced to a minimum and addresses most signal treatment to the software. This way, the complete electronics is enclosed in the array's housing and easily is connected to the notebook via USB-wire.

\section{Acknowledgements}

The presented work partially is supported by the Bundesministerium für Bildung und Forschung in the project group AL-CAST. 


\section{References}

[1] Mook, G.; Hesse, O.; Uchanin, V.: Deep Penetrating Eddy Currents and Probes. 9. ECNDT, Berlin, 25.-29.9.2006, paper 176

[2] Yashan, A.; Bisle, W.; Meier, Th.: Inspection of Hidden Defects in Metal-Metal Joints of Aircraft Structures Using Eddy Current Technique with GMR Sensor Array. Proc. $9^{\text {th }}$ ECNDT, Berlin, 2006, paper Tu.4.4.4

[3] Vacher, F.; Gilles-Pascaud, C.; Decitre, J.M.; Fermon, C.; Pannetier, M.; Cattiaux, G.: Non Destructive Testing with GMR Magnetic Sensor Arrays. Proc. $9^{\text {th }}$ ECNDT, Berlin, 2006, paper Tu.4.4.2

[4] Thomas, H.-M.; Weigelt, G.: Anwendung von Wirbelstromverfahren zur quantitativen Bestimmung der Tiefenausdehnung von Korrosionsschäden an Aluminiumstrukturen. DECHEMA-Final report, 11L08-4. 1991

[5] Mook, G.: Bildgebende Wirbelstromprüfung. 27. Proc. of Krajowa Konferencja Badan Nieniszczacych, Miedzyzdroje, October 1998, pp. 197-205.

[6] Gramz, M.; Stepinski,T.: Eddy Current Imaging array sensors and flaw reconstruction. Research in Nondestructive Evaluation, 5, (1994), pp. $157-174$

[7] Feist, W. D.; Mook, G.; Hinken, J. H.; Simonin, J.; Wrobel, H.: Electromagnetic detection and characterization of tungsten carbide inclusions in non-ferromagnetic alloys. Advanced Engineering Materials 7 (2005) 9, pp 841-846

[8] Mook, G.; Pohl, J.; Michel, F.: Non-destructive characterization of smart CFRP structures. Smart Mater. Struct. 12 (2003) pp. 997-1004

[9] Scholz, A.: Sondenmatte - neuer Weg für die Oberflächenprüfung mit Wirbelstrom. Proc. DGZfP Annl. Conf. Trier May 1990. pp. 218-22.

[10] Grimberg, R.; Savin, A.; Leitoiu, S.; Bruma, A.; Steigmann, R.; Udpa, L.; Udpa, S.: Automated Eddy Current Data Analysis. $4^{\text {th }}$ International Conference on NDT, Hellenic Society for NDT, Chania, Crete-Greece, 11-14 October 2007

[11] Pelletier, E.; Grenier, M.; Chahbaz, A.; Bourgelas, T.: Array Eddy Current for Fatigue Crack Detection of Aircraft Skin Structures. Proc. $V^{\text {th }}$ International Workshop, Advances in Signal Processing for Non Destructive Evaluation of Materials. Québec City (Canada), 2-4 Aug. 2005

[12] Sollier, T., Talvard, M., Aïd, M.: Use of EC Sensor Arrays on Thin Films. Electromagnetic Nondestructive Evaluation (IV), S.S. Upda et al. (Eds.), IOS Press, 2000

[13] Gilles-Pascaud, C.; Lorecki B.; Pierantoni, M.: Eddy current array probe development for nondestructive testing. $16^{\text {th }}$ World Conference on NDT, Montreal, Canada Aug 30 - Sep 3, 2004

[14] Joubert, P.-Y.; Le Diraison, Y.; Pinassaud, J.; Satie, L.: Eddy Current Imager for the Detection of Buried Flaws in Large Metallic Structures. Proc. $9^{\text {th }}$ ECNDT, Berlin, 2006, paper Tu.3.6.1

[15] Perez, L.; Dolabdjian, C.; Waché, C.W.; Butin, L.: Advance in magnetoresistance magnetometer performances applied in eddy current sensor arrays. $16^{\text {th }}$ World Conference on NDT, Montreal, Canada, Aug 30 - Sep 3, 2004

[16] Decitre, J.-M.; Premel, D.; Mangenet, G.; Juliac, E.; Feist, W.D.: Flexible EC Array Probe for the Inspection of Complex Parts developed within the European VERDICT Project. Proc. $9^{\text {th }}$ ECNDT, Berlin, 2006, paper Tu.4.4.3 
[17] Gilles-Pascaud C.; Lorecki B.; Pierantoni M.: Eddy Current Array Probe Development for Nondestructive Testing. $16^{\text {th }}$ World Conference on NDT, Montreal, Canada, Aug 30 - Sep 3, 2004

[18] Meilland, P.: Novel Multiplexed Eddy-Current Array for Surface Crack Detection on Rough Steel Surface. Proc. $9^{\text {th }}$ ECNDT, Berlin, 2006, paper Tu.4.8.1

[19] Sullivan, S.P.; Cecco, V.S.; Obrutsky, L.S.; Lakhan, J.R.; Park, A.H.: Validating Eddy Current Array Probes for Inspecting Steam Generator Tubes. ndt.net 1998 January, Vol.3 No.1

[20] Zilberstein, V.; Goldfine, N.; Washabaugh, A.; Weiss V.; Grundy, D.: The use of fatigue monitoring MWM-arrays in production of NDI-Standards with real fatigue cracks for reliability studies. $16^{\text {th }}$ World Conference on NDT, Montreal, Canada, Aug 30 - Sep 3, 2004

[21] Lafontaine, G.; Samson, R.: Eddy Current Array Probes for Faster, Better and Cheaper Inspections. ndt.net, October 2000, Vol. 5 No. 10

[22] Reimche, W. et al.: Development and Qualification of a Process-Oriented Nondestructive Test Method for Weld Joints to Operate with Remote Field Eddy Current Technique. Proc. ${ }^{\text {th }}$ ECNDT, Berlin, 2006, paper Fr.1.7.2

[23] Mook, G.; Michel, F.; Simonin, J.; Krüger, M.; Luther, M.: Subsurface Imaging using Moving Electromagnetic Fields and Surface Acoustic Waves. $4^{\text {th }}$ International Conference in NonDestructive Testing, Stuttgart, Germany, April 2-4, 2007

[24] Mook, G.; Michel, F.; Simonin, J.; Krüger, M.; Luther, M.: Visualization of Hidden Anomalies. $2^{\text {nd }}$ Dresden Airport Seminar: Reliability, Testing, Monitoring of Aerospace Components. Airport Dresden, 15. November 2006

[25] Mook, G.; Michel, F.; Simonin, J.: Wirbelstrom-Bewegtfeldsensoren - Potenziale für die industrielle Anwendung. ZfP in Forschung, Entwicklung und Anwendung, DACH-Jahrestagung, St. Gallen, 28.-30.4.2008, Mo.3.B.1

[26] Mook, G.; Simonin, J.: Eddy current tools for education and innovation. $17^{\text {th }}$ World Conference on Non-destructive Testing, paper 379, Shanghai, Oct. 25-28, 2008

[27] Mook, G.; Michel, F.; Simonin, J.: Electromagnetic imaging using probe arrays. $17^{\text {th }}$ World Conference on Non-destructive Testing, paper 380, Shanghai, Oct. 25-28, 2008

[28] Mook, G.; Michel, F.; Simonin, J.: Wirbelstrom-Sensorarrays für den Blick unter die Oberfläche. Berichtsband des 10. Kolloquiums Werkstoff- und Bauteilprüfung in der Schweißtechnik, Schweißtechnische Lehr- und Versuchsanstalt Halle, 01.10.2008

[29] Mook, G.; Michel, F.; Simonin, J.: Bildgebende Verfahren zur Prüfung auf oberflächennahe Fehler mittels Wirbelstrom-Sensorarrays. ZfP in Forschung, Entwicklung und Anwendung, DGZfPJahrestagung, Münster, 18.-20.5.2009, Mo.3.B.1

[30] Mook, G.; Michel, F.; Simonin, J.: Wirbelstrom-Sensorarrays. ZfP in Forschung, Entwicklung und Anwendung, DGZfP-Jahrestagung, Münster, 18.-20.5.2009, P20 